\title{
ENERGY MANAGEMENT OF LOAD WITH SEVERAL ENERGY SOURCES
}

\author{
Sonja Susac, Mile Medjugorac, Petar Maric, Ivan Bevanda \& Drago Bago
}
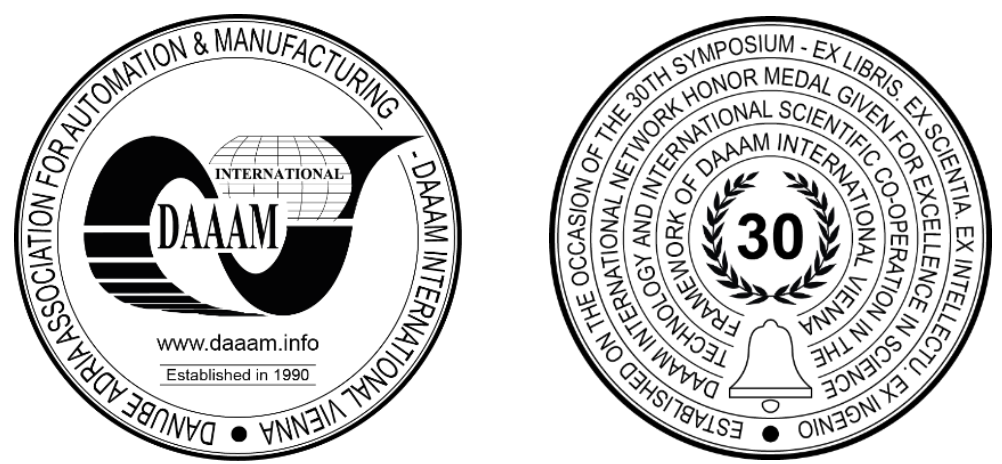

This Publication has to be referred as: Susac, S[onja]; Medjugorac, M[ile]; Maric, P[etar]; Bevanda, I[van] \& Bago, D[rago] (2020). Energy Management of Load with Several Energy Sources, Proceedings of the 31st DAAAM International Symposium, pp.0899-0906, B. Katalinic (Ed.), Published by DAAAM International, ISBN 978-3-90273429-7, ISSN 1726-9679, Vienna, Austria

DOI: $10.2507 / 31$ st.daaam.proceedings. 125

\begin{abstract}
This paper will describe energy management of load with several energy sources. Electrical energy consumption of business building in property of JP EPHZHB d.d. Mostar in Tomislavgrad represents a load. Photovoltaic power plant, battery storage system and electrical distribution network represents different energy sources. Load and energy sources are all connected on joint busbar in a low-voltage free-standing electrical cabinet. The authors will present energy management when PV plant and battery storage system are operating in parallel with the distribution network to supply the demanded load. Also, the conditions necessary for PV plant and battery storage system to supply the demanded load without operation with distribution network will be presented.
\end{abstract}

Keywords: energy management; PV plant; battery storage system; load

\section{Introduction}

The term microgrid should not be associated with the size of the network but with the functions that the network possesses. Microgrids are defined as distribution systems with distributed energy sources, energy storage and controllable load, which operate connected to the main network or in island operation in a controlled and coordinated manner. The connection point is called the Point of Common Coupling (PCC).

Microgrid typically operates in parallel with the main grid and then adjusts the balancing of power requirements and power delivery by taking power from the main grid or giving power to the main grid for maximum economic benefit. In this mode, the voltage requirements and the power flow requirements are considered at the same time, especially in the PCC. In island operation, the microgrid is isolated from the main grid. Then the highest priority of the microgrid is to maintain a reliable supply of customers instead of economic benefits [1].

Accordingly, in island mode, the goal is a maximum rate of fulfilment of consumption requirements with minimum work costs. This means, for example, that the production of wind turbines and photovoltaic power plants should always be used to compensate the lack of electricity and that part of the load must be able to be switched off for power balancing when necessary. Microgrid typically requires an energy management strategy - assigning a reference to active and reactive power and ensuring that controllable units work together. 
Key problem that arises in microgrid energy management is the fluctuation of distributed generation. To reduce fluctuations in distributed generation, we use various control mechanisms in microgrids, such as regulating the power of each unit of distributed generation, regulating the charging, and discharging of the battery storage system as well as load shedding.

\section{Microgrid at the location of EPHZHB office building in Tomislavgrad}

The microgrid at the location of the EPHZHB office building in Tomislavgrad consists of the office building in Tomislavgrad, which represents the consumer (controllable load), photovoltaic power plant Vuciji Brig as a distributed energy source and the battery storage system (energy storage). The microgrid is connected to the main distribution network in a stand-alone connection and metering cabinet (abbreviation in original language: SPMO).

\subsection{Photovoltaic power plant Vuciji brig}

Photovoltaic power plant Vuciji brig has an installed power of 49,8 kWp (166 monocrystalline PV modules with a unit power of $300 \mathrm{Wp}$ ), and photovoltaic modules are connected to three DC/AC inverters where two inverters are with rated active power of $20 \mathrm{~kW}(2 \times 4$ strings of PV modules - total 2x69 PV modules) while the third inverter is with rated active power of $10 \mathrm{~kW}$ ( 2 strings of PV modules - a total of $28 \mathrm{PV}$ modules). The system of photovoltaic modules was constructed on two locations: two eaves of the parking lot of the main building and the roof of the auxiliary building [2].

Electricity obtained from photovoltaic modules is used for the needs of building consumption, for charging batteries or is given to the distribution network. The photovoltaic system must have protection against island operation, as is the case for standard photovoltaic power plants connected to the distribution network.

\subsection{Battery storage system}

In addition to the main building in Tomislavgrad, there is an auxiliary building in which a battery storage system is installed. The system consists of lithium-ion battery cells with a total capacity of $32 \mathrm{kWh}$ (100 cells with a capacity of $0,32 \mathrm{kWh}$ each and a voltage of 3,2 V in the charged state) [3]. The battery cells are connected in series with the associated battery management system, which includes monitoring the voltage, current and temperature of the batteries and autonomous response when the appropriate voltage or temperature limits are exceeded during charging or discharging, to ensure safe operation. The batteries are connected to a DC/AC converter that is controlled by the charging current of the battery pack with derivative protection elements to protect against overcharging or over discharging of the battery pack. The DC/AC converter is connected to a battery controller with the ability to communicate to the BMS (Building Management System) using one of the standard communication protocols that must be of adequate computing power to perform algorithms for estimating the state and parameters of the battery record and calculating the required charging current. The controller receives a control command from the BMS on the amount of energy that the battery system needs to exchange with the network at a given time.

The battery storage system is connected to the BMS and sends data on state of the battery system: charging/discharging current, temperature of each cell, voltage of each cell, total voltage of the battery system. Battery system status data is transferred to a central database. The battery storage system must prevent the injection of electricity from the batteries into the distribution network (building) if there is no mains voltage (for example planned or unplanned outage of the distribution network), which means the battery system must have protection against island operation.

\subsection{EPHZHB office building in Tomislavgrad}

The EPHZHB office building in Tomislavgrad is spread over $1000 \mathrm{~m}^{2}$ (ground floor and first floor). The building has been in operation since 2013, and consists of office spaces, meeting room, control room, IT room and other ancillary spaces [2]. When preparing media for heating and cooling the space in the building, two sources are used: the primary energy source for heating and cooling is a heat pump, while the secondary energy source for heating is an electric thermoblock. The distribution of thermal energy in the building is performed using parapet fan coil units and ceiling fan coil units. For the meeting room on the ground floor and the room of the control center on the first floor, fresh air is provided via two air-conditioning chambers.

\subsection{Stand-alone connection and metering cabinet}

SPMO is the meeting point of the connection; that is the place of energy exchange on the one hand of the consumer set (EPHZHB office building), distributed generation (PV plant Vuciji Brig), energy storage (battery system) and distribution network on the other hand.

\subsection{Distribution network in Tomislavgrad}

The EPHZHB office building is supplied from the distribution network which starts at the $110 / 35 / 10(20) \mathrm{kV}$ Tomislavgrad transformer station. The medium voltage $10 \mathrm{kV}$ terminal of the transformer station Tomislavgrad KO Latice 
(KO stands for cable) primarily supplies the transformer station on the location of the EPHZHB business building (MBTS Vuciji Brig 10(20)/0,4 kV). Power supply of the office building is also possible via a medium voltage $10 \mathrm{kV}$ terminal KO Plastika. From MBTS Vuciji Brig (MBTS stands for ground-mounted distribution substation), a 0,4 kV LV cable extends to SPMO - connection measuring point of the office building [2].

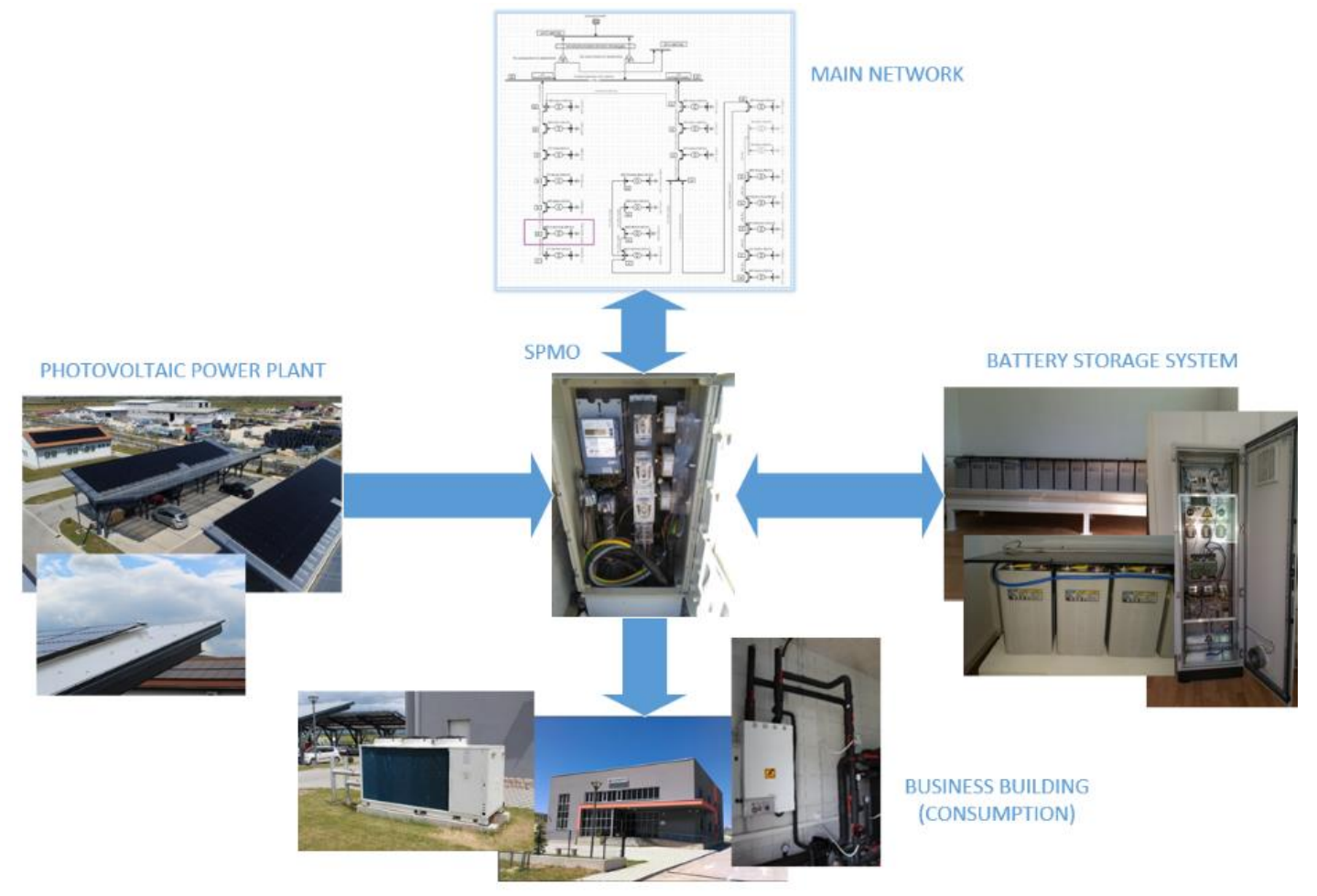

Fig. 1. Microgrid at the location of EPHZHB business building in Tomislavgrad

\section{Island operation of microgrid}

In island operation, the microgrid uses a photovoltaic power plant and a battery system to fulfil the building's consumption requirements. We describe a photovoltaic power plant with output power. Let $P_{P V_{r a t}}$ be the rated power of the photovoltaic power plant, and $P_{P V_{o u t}}$ the current output power of the photovoltaic power plant. Equation (1) is always valid:

$$
0(t) \leq P_{P V_{\text {out }}}(t) \leq P_{P V_{\text {rat }}}(t)
$$

The rated power of the photovoltaic power plant is $49,8 \mathrm{kWp}$. According to [4], the current output power of the photovoltaic power plant $P_{P V_{\text {out }}}$ can be described by (2):

$$
P_{P V_{\text {out }}}(t)=P_{S T C} \frac{G_{C}(t)}{G_{S T C}}\left[1+k\left(T_{C}(t)-T_{S T C}\right)\right]
$$

STC (Standard Test Conditions) are conditions where the solar radiation $G_{S T C}$ is $1000 \mathrm{~W} / \mathrm{m}^{2}$, the cell temperature $T_{S T C}$ is $25^{\circ} \mathrm{C}$, and the relative atmospheric optical quality $A M$ is $1.5 . G_{C}$ is the solar irradiation of the operating point, $k$ is the temperature power coefficient of PV plant, $P_{S T C}$ is the rated power at STC, and $T_{C}$ is the operating point temperature. The battery system is described by the output power and state of charge and the voltage limitation condition. The power of a battery system can be described by (3):

$$
P_{\text {batt_discharge_max }}(t) \leq P_{\text {batt }} \text { out }(t) \leq P_{\text {batt_charge_max }}(t)
$$

where $P_{\text {batt_discharge_max }}$ is the maximum discharge power represented by the negative sign (-), $P_{\text {batt }}$ out is the current output power of the battery system, and $P_{\text {batt_charge_max }}$ is the maximum charging power represented by the positive sign $(+)$. The maximum discharge power is $-10 \mathrm{~kW}$, while the maximum charge power is $+10 \mathrm{~kW}$. Cable and battery inverter losses were ignored. The state of charge of the battery system can be described by (4): 


$$
S O C_{\min }(t) \leq S O C(t) \leq S O C_{\max }(t)
$$

where $S O C_{\min }$ is the minimum charge state of $0 \mathrm{kWh}$ or $0 \mathrm{Ah}$ or $0 \%, S O C$ is the current charge state, and $S O C_{\max }$ is the maximum charge state of $32 \mathrm{kWh}$ or $100 \mathrm{Ah}$ or $100 \%$. The voltage of each battery cell always must be within the specified limits between the minimum and maximum voltage, equation (5):

$$
U_{\text {batt_unit } t_{\text {min }}}(t) \leq U_{\text {batt_unit }}(t) \leq U_{\text {batt_unit }_{\text {max }}}(t)
$$

In island operation, (6) should always be valid:

$$
P_{\text {load }}(t)=P_{P V_{\text {out }}}(t)+P_{\text {batt }} \text { out }(t)
$$

where $P_{\text {load }}(t)$ is the current electricity consumption of the building. According to (6), the balance between consumption and production must always be valid under the satisfied conditions in equations (1), (2), (3), (4) and (5). Of course, distributed sources in their work must respect the network rules of the distribution system operator to whose distribution network they are connected.

\section{Analysis of microgrid functioning in island operation}

The microgrid in Tomislavgrad operates in parallel with the distribution network. The building uses the main network, a photovoltaic power plant and a battery system for electricity consumption. To show the possibilities of microgrid functioning in island operation, an experiment was conducted with the aim of maximizing the use of PV plant and battery system and minimizing the use of electricity from the main grid. The experiment was conducted during the working week, on Wednesday $17^{\text {th }}$ June 2020, Thursday $18^{\text {th }}$ June 2020 and Friday $19^{\text {th }}$ June 2020. It is important to emphasize that the largest consumers of electricity in the building are devices used to produce heating and cooling energy to provide the required temperature conditions in the premises of the building. These are:

1) Heat pump - used in both the heating season and the cooling season YORK YLHA 80T, rated electrical power: 32,6 kW

2) Electric thermo-block - used only in the heating season Thermo Extra $88 \mathrm{~kW}$, rated electrical power: $88 \mathrm{~kW}$

During the experiment, the building did not use heating or cooling systems, so energy consumption was significantly lower than in the case of using the heating and cooling system of the building. This transition period occurs on a larger number of working days in May, June, and September.

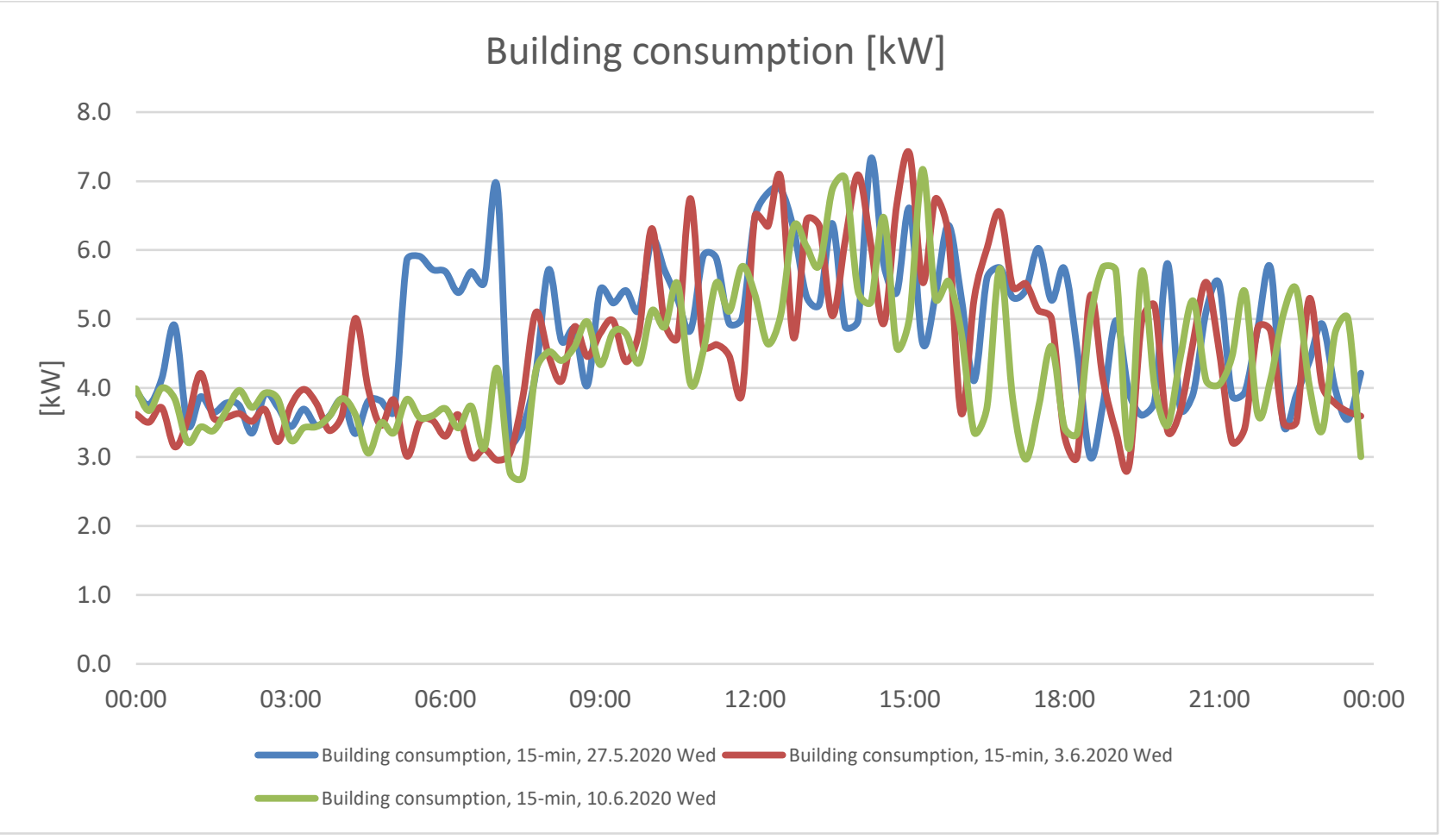

Fig. 2. Building consumption for 3 working days during transition period 
There are 15 employees in the building during working hours from 08:00 am to 04:00 pm, whose working hours are from 08:00 am to 04:00 pm. In addition to these employees, 1 employee of the security company stays in the building throughout the day (from 0:00 am to 11:59 pm). Electricity consumers in the transition period are computers, printers, interior lighting, air conditioning for the server room, fire alarm system, burglar alarm system, etc. Figure 2 shows the realized consumption of the building on $27^{\text {th }}$ May 2020 (Wednesday), $3^{\text {rd }}$ June 2020 (Wednesday) and $10^{\text {th }}$ June 2020 (Wednesday), for 3 characteristic working days. There is a minimum load of about $3 \mathrm{~kW}$, a maximum load of about 7,5 $\mathrm{kW}$ and an increase in load during working hours from 08:00 am to 04:00 pm.

In order to maximize the use of energy from the PV plant and the battery system and get closer to the functioning of the microgrid in island operation, it is necessary to use electricity from the battery system to fulfil the electricity consumption of the building at times when the amount of radiation is $0 \mathrm{~W} / \mathrm{m}^{2}$ and to use electricity from photovoltaic power plants to fulfil the electricity consumption of the building at times when the radiation is greater than $0 \mathrm{~W} / \mathrm{m}^{2}$. The trends of external conditions affecting PV plant production are shown in Figures 3 and 4.

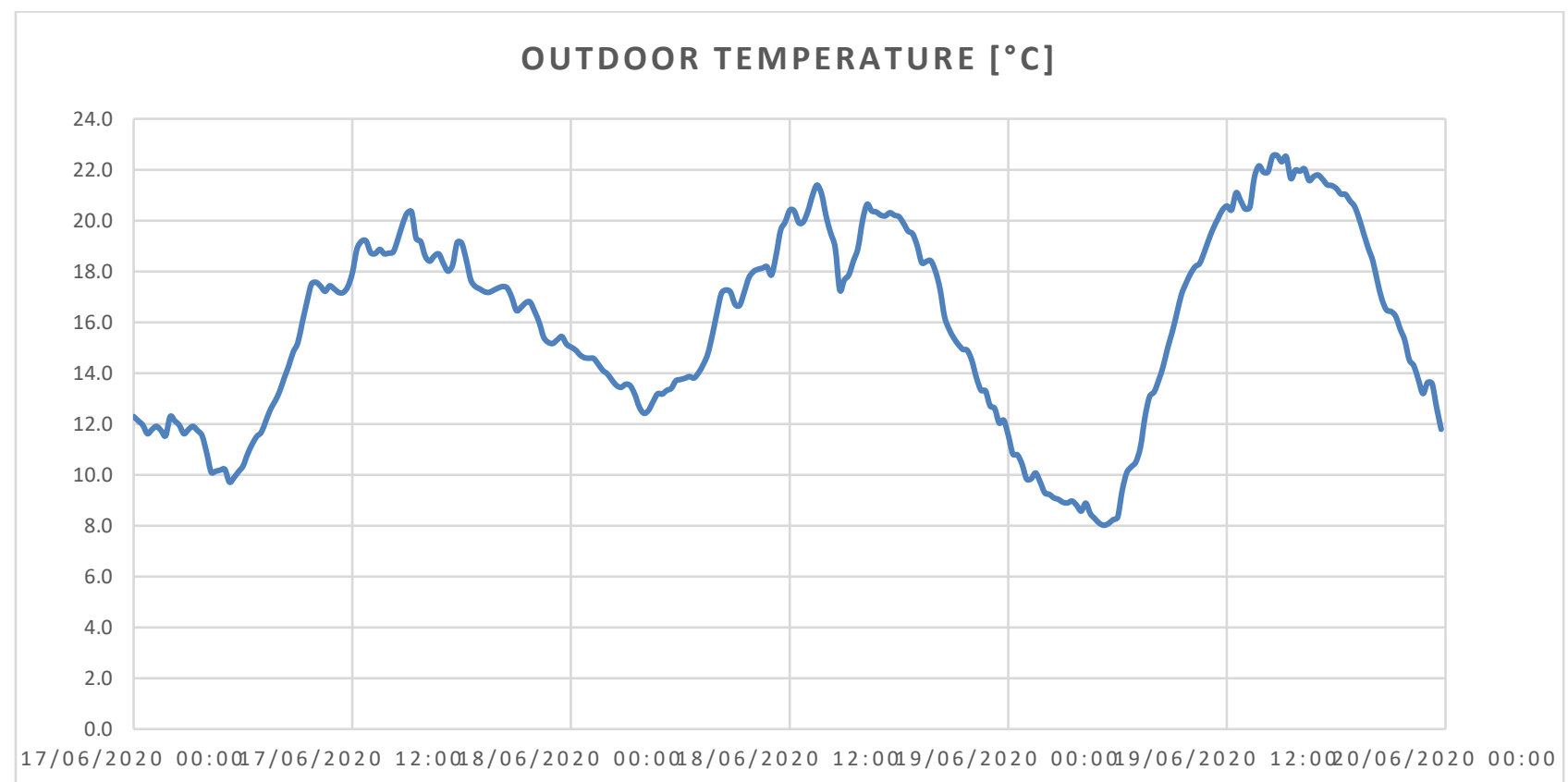

Fig. 3. Graphic of outdoor temperature

SOLAR RADIATION [W/M²]

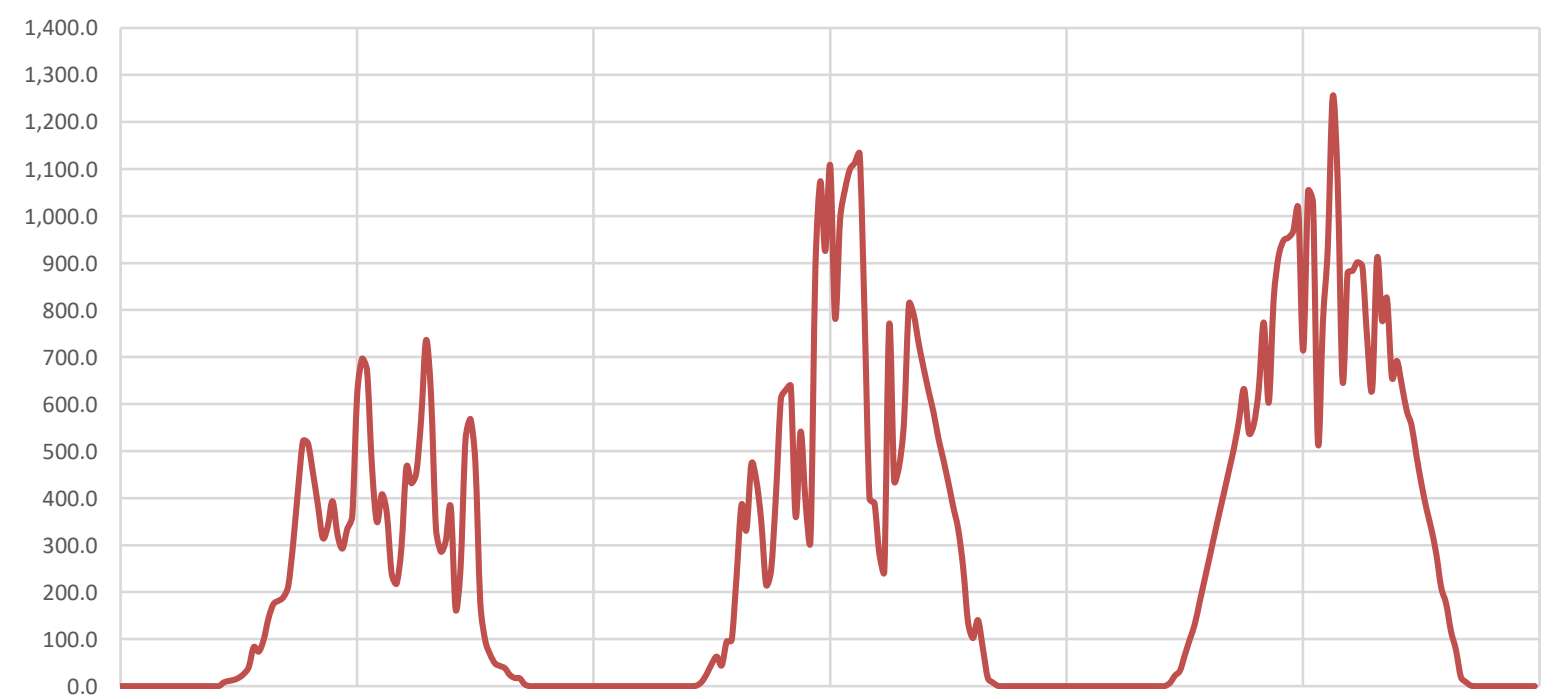

17/06/2020 00:0017/06/2020 12:0018/06/202000:0018/06/2020 12:0019/06/202000:0019/06/2020 12:0020/06/2020 00:00

Fig. 4. Graphic of solar radiation 
Figures 3 and 4 show that the outside temperature and radiation had the lowest values on Wednesday and the highest on Friday. Charging and discharging the battery system was initiated by a command from a server computer in Tomislavgrad from Command Prompt (CMD). A command is run in the CMD that calls out the created program code in Python that is used to set power references to the battery inverter. The batteries were discharged in the evening and early morning. The batteries were charged during the day when the radiation was increased. The results are shown in Figure 5 and Table 1.

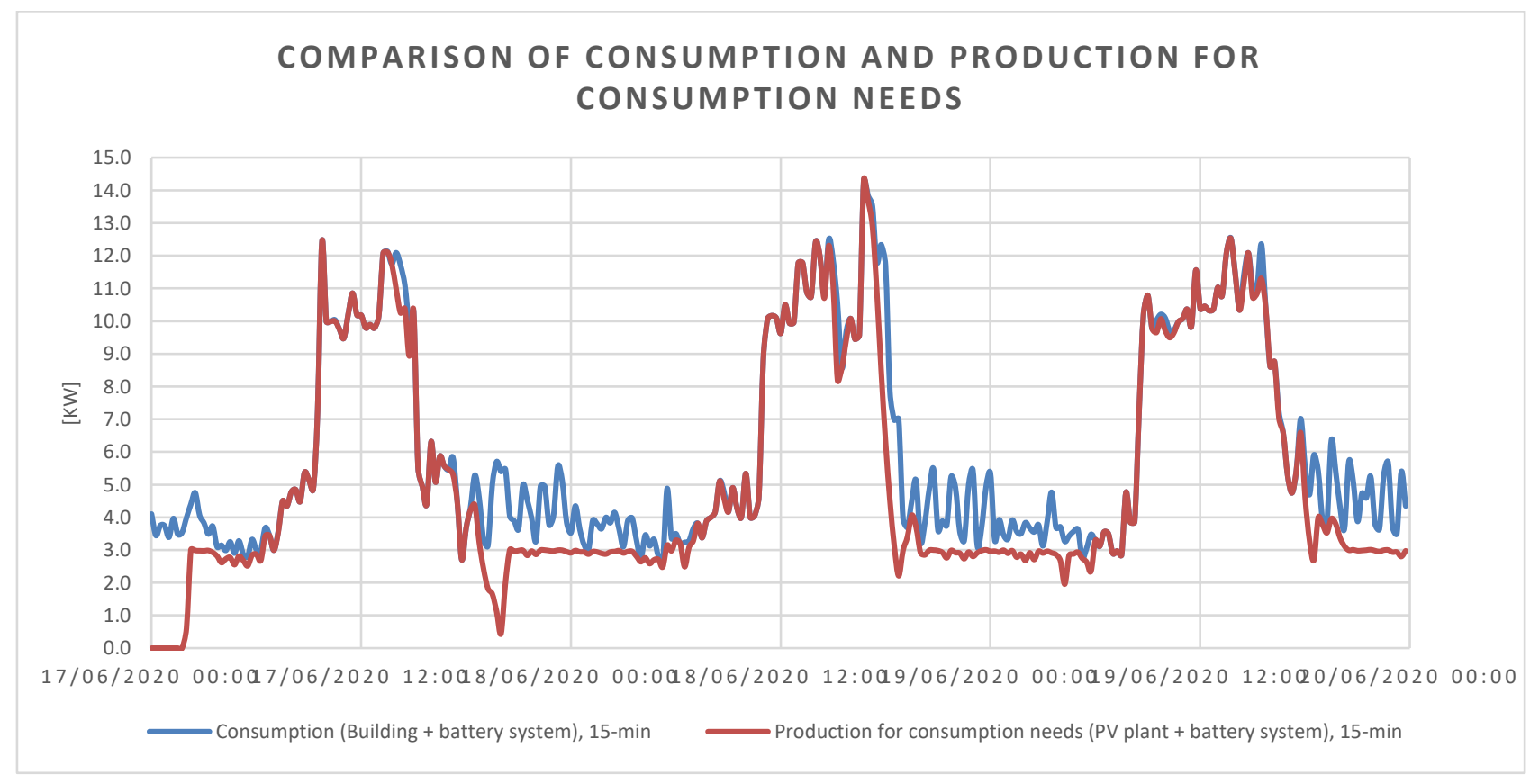

Fig. 5. Comparison of consumption and production for consumption needs

\begin{tabular}{|c|c|c|c|}
\hline Date & $\begin{array}{c}\text { Consumption (Building }+ \\
\text { battery system) }[\mathrm{kWh}]\end{array}$ & $\begin{array}{c}\text { Production for consumption } \\
\text { needs (PV plant + battery } \\
\text { system) }[\mathrm{kWh}]\end{array}$ & $\begin{array}{c}\text { Production share for } \\
\text { consumption needs }\end{array}$ \\
\hline $\begin{array}{c}17^{\text {th }} \text { June 2020 } \\
\text { Wednesday }\end{array}$ & 136,74 & 114,72 & $84 \%$ \\
\hline $\begin{array}{c}18^{\text {th }} \text { June 2020 } \\
\text { Thursday }\end{array}$ & 148,22 & 130,96 & $80 \%$ \\
\hline $\begin{array}{c}19^{\text {th }} \text { June 2020 } \\
\text { Friday }\end{array}$ & 151,76 & 136,81 & $90 \%$ \\
\hline
\end{tabular}

Table 1. Comparison of consumption and production for consumption needs

From the presented results it is evident that for all 3 observed working days a large share of production from PV plant and battery system (battery discharge) for the needs of building consumption and battery system (battery charging) was achieved. Compared to the previously analysed working days, the load on the building increased by the amount of reference battery charging power (from $5 \mathrm{~kW}$ to $8 \mathrm{~kW}$ ). The batteries were discharged with a power of $3 \mathrm{~kW}$ or the power of the minimum load of the building. Since the capacity of the battery system is $32 \mathrm{kWh}$, by discharging $3 \mathrm{~kW}$, the batteries could supply the building's consumption for just over 10 hours during the night and early morning.

In order to achieve a complete balance or condition for the functioning of the microgrid in island mode, it is necessary to use advanced microgrid management systems in island mode that are based on the foundations of predictive automatic control and advanced information and communication technologies.

\section{Microgrid management in island mode}

In the literature, we can find several different approaches and strategies used to manage electricity in the microgrid. Some of them are based on a conventional centralized energy management system. Such a centralized system consists of a communication channel that monitors renewable energy sources whereby the higher-level controller sends control commands to the local controller to optimize energy consumption. In this paper, a power grid management strategy based on predictive power management of battery charging and discharging is proposed. 
Such an MPC (Model Predictive Control) algorithm considers the energy requirements of consumers and the predictive value of photovoltaic power plant production. The predictive control model is a discrete control strategy where for each time pattern the optimal open loop control problem for some predefined predictive horizon of $N$ steps is solved. The solution for the optimal control problem is generated in the form of a profile of control variables for each time sample $u_{k}, u_{k+1}, \ldots . . u_{k+N-1}$ in such a way that the control signals and the predicted process behavior minimize important parametric performance in relation to the system model and all its conditions. The first control command $u_{k}$ from the generated control sequence is applied to the system and the whole process is repeated at time $t_{k+1}$ [5].

Although the methods used to minimize the target function and control the conditions for the control signals can be quite different, the MPC combines feedback control and optimal control. Since the control of a system or process is subject to major changes, it is not realistic to expect a solution to the optimal open-loop management problem over a long time horizon and the application of control variable profiles for the entire horizon. Nevertheless, the model of predictive control using feedback as a stabilizing factor that minimizes the objective function under certain conditions can solve the optimal open loop control problem [6].

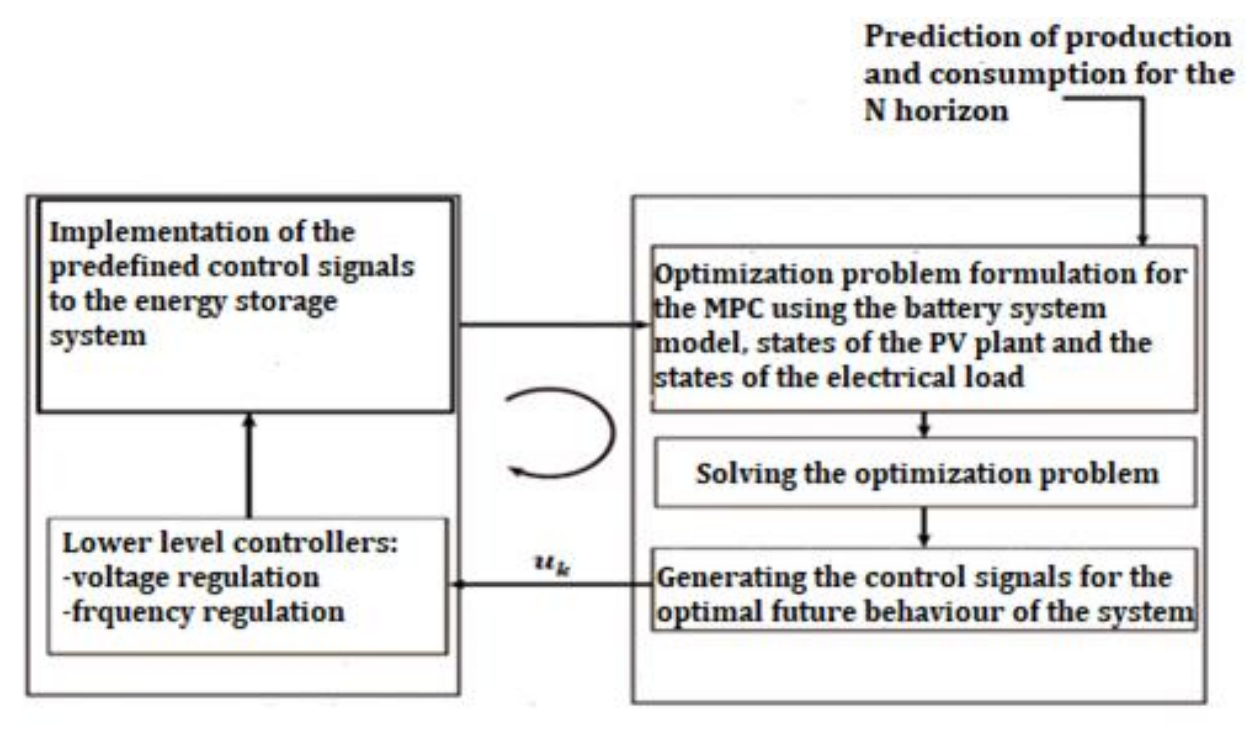

Fig. 6. Schematic representation of the proposed MPC microgrid management strategy in island mode

In microgrid in island mode, the input variables to the predictive control model algorithm are the sampled states of the battery system, photovoltaic power plant production and energy demand by the consumer at some time $t_{k}$ and their estimated values for $N$ steps in the future. The output values from the algorithm are the setpoints or setpoints of the battery system inverter that guarantee optimal system behavior in the future with respect to the given optimization problem. In this paper, a predictive control model algorithm is proposed to maximize operational efficiency, use renewable energy, and minimize battery system degradation. Within this context, a goal function can be selected for the specified optimization problem [7]:

$$
J=\sum_{i=k}^{k+N} \omega_{s o c} \cdot S O C_{b a t}(i)^{2}+\omega_{d b a t} \cdot\left(S O C_{b a t}(i+1)-S O C_{b a t}(i)\right)^{2}
$$

where $\omega_{s o c}$ and $\omega_{\text {dbat }}$ are the weight factors of the state of charge of the battery $S O C_{b a t}(i)$ and the degradation of the battery system. This target function does not explicitly penalize the charging or discharging power of the battery system $P_{\text {batt }}$ out $(t)$ and therefore all surplus power output of the photovoltaic power plant will move towards the batteries leading to their increased use. In terms of operational efficiency, increased use of the battery system is useful since the efficiency of the battery system discharge cycle is about $90 \%$. However, battery degradation should be minimized as much as possible while using the battery system.

The weight factor $\omega_{s o c}$ is used to penalize longer periods of high charge values $S O C_{b a t}(i)$ of batteries while the weight factor $\omega_{\text {dbat }}$ is used to penalize the charge/discharge cycle as excessive charging or discharging of batteries has been found to contribute to greater cyclical degradation of the system itself. Although (6) appears to penalize the SOC variable, it indirectly modifies the variable $P_{\text {batt }_{\text {out }}}(t)$ to ensure minimization of the stated target function. Also, by including the predicted power output values of the photovoltaic power plant and the electrical load for the next predictive control horizon, it can contribute to better reduction of battery degradation by changing the charge/discharge cycle and the minimum possible high retention time of the battery system. 


\section{Conclusion}

Microgrid is a functional unit made up of distributed sources, energy storage and consumers. The microgrid can work in parallel with the main network or independently, in island operation. It is defined by function, not by size. The earliest electric networks were basically microgrids before they merged into national or regional networks; the concept of the microgrid is not new. But their role is now changing and expanding due to growing energy demands, falling renewable energy prices, and the growing need for resilience and power autonomy both online and offline.

The observed microgrid at the location of the EPHZHB business building in Tomislavgrad consists of an office building in Tomislavgrad (consumer), the Vuciji Brig photovoltaic power plant (distributed energy source), and a battery storage system (energy storage). The unique point of connection of the microgrid to the distribution network is in a freestanding connection and metering cabinet (meeting point of connection - PCC).

The paper shows an experiment of microgrid functioning in island mode with the aim of minimal use of electricity from the grid, or maximum use of PV plant and battery system. The experiment was conducted in three working days and enviable results were achieved in terms of coverage of total building consumption through the operation of the FNE and the battery system.

The paper proposes a strategy for energy management in a microgrid based on a model predictive control algorithm. The strategy envisages separate modelling of the battery system of the micro grid, while predictive information on future values of photovoltaic power plant production and electrical load of the building can be approximated according to daily patterns of electricity production and consumption. The purpose of making a battery system model is to predict the future values of the charge state depending on the change of the control variables of charging or discharging the battery system. Based on the estimated values of the mentioned variables in the microgrid, the algorithm of the predictive control model issues and corrects control commands at appropriate time intervals to better distribute the produced electricity between the building load and the battery system and to prevent battery system degradation due to more frequent charging cycles and discharge.

The modern society reached another development stage where over time, as energy become an increasingly digital given with sensors, while also becoming more decentralized with energy coming from a local solar photovoltaic, wind or microgrid systems, users are able to have even more control and ability to manage their energy usage [8]. During the three working days of the experiment, the following results of the coverage of consumption by production from the photovoltaic power plant and the battery system were achieved: Wednesday $84 \%$, Thursday $88 \%$, Friday $90 \%$.

\section{References}

[1] Jiang, Q.; Xue, M. \& Geng, G. (2013). IEEE Transactions on Power Systems, Vol. 28, No. 3, August 2013.

[2] Medjugorac, M. (2019). Description of the 3Smart technical solution on the EPHZHB office building and distribution network, Opis 3Smart tehničkog rješenja na poslovnoj zgradi EPHZHB i distribucijskoj mreži, Public presentation of 3Smart pilot project in Bosnia and Herzegovina, Mostar, July 2019

[3] Medjugorac, M. (2018). Realisation of 3Smart project at EPHZHB business building site in Tomislavgrad, 1st conference BH K/O CIRED, Mostar, October 2018

[4] Zhao, B.; Zhang, X.; Chen, J. \& Wang, C. (2013). IEEE Transactions on Sustainable Energy, Vol. 4, No. 4, September 2013

[5] Oh, S.; Chae, S.; Neely, J.; Baek, J. \& Cook, M. (2017). Efficient Model Predictive Control Strategies for Resource Management in an Islanded Microgrid. Energies. 10. 1008. 10.3390/en10071008.

[6] Mayhorn, E.; Kalsi, K.; Elizondo, M.; Zhang, W.; Lu, S.; Samaan, N. \& Butler-Purry, K. (2012). Optimal control of distributed energy resources using model predictive control. In Proceedings of the IEEE Power and Energy Society General Meeting, San Diego, CA, USA

[7] Nair, U. R. \& Costa-Castelló, R. (2020). A Model Predictive Control-Based Energy Management Scheme for Hybrid Storage System in Islanded Microgrids, IEEE Access, vol. 8, pp. 97809-97822, 2020, doi: 10.1109/ACCESS.2020.2996434.

[8] Medojevic, M.; Díaz Villar, P.; Cosic, I.; Rikalovic, A.; Sremcev, N. \& Lazarevic, M. (2018). Energy Management in Industry 4.0 Ecosystem: a Review on Possibilities and Concerns, Proceedings of the 29th DAAAM International Symposium, pp.0674-0680, B. Katalinic (Ed.), Published by DAAAM International, ISBN 978-3-902734-20-4, ISSN 1726-9679, Vienna, Austria, DOI: 10.2507/29th.daaam.proceedings.097 